\title{
Expansores Tisulares: Conceptos Generales
}

\author{
Madelein Centeno-Rodríguez, ${ }^{1}$ Carlos Alberto Centeno-Ramírez ${ }^{2}$
}

El proceso de expansión tisular puede definirse como la habilidad del tejido vivo de aumentar su área de superficie como respuesta a la presión ejercida por una masa creciente $^{1}$ y se basa en el principio de que el tejido blando habitualmente responde a las fuerzas internas y externas para cambiar su forma y tamaño, independientemente de la edad. ${ }^{2.3}$ El embarazo, la obesidad, el crecimiento esquelético normal, hematomas, hidrocefalia y el crecimiento tumoral son ejemplos claros de este concepto. ${ }^{2.45}$

Desde el año 1957, cuando iniciaron las primeras experiencias con este tipo de procedimientos, la expansión tisular se ha convertido en una técnica muy utilizada en cirugía reconstructiva ya que permite la creación de gran cantidad de tejido blando para corregir defectos, brindando un excelente resultado.

El objetivo de la expansión tisular radica en lograr el desarrollo de un área donadora de tejido con características similares al área donde está el defecto en cuanto a textura, color, grosor y sensibilidad, que permita la reconstrucción con cicatriz única poco evidente y preservando estéticamente el sitio donador. ${ }^{1.99}$

\section{Historia}

En 1957, Neumann realizó el primer intento documentado de este tipo de procedimientos, al tratar de reconstruir una oreja utilizando un novedoso instrumento de goma el cual se colocaba bajo la piel y se inflaba mediante la inyección de líquido a través de tubos que comunicaban con el exterior. De aquí nació el término "expansión tisular"."

Descriptores: Expansión tisular, expansores tisulares, tissue expansion, tissue expanders.

Recibido: 27 de abril de 2000

Aceptado: 28 de agosto de 2000

\section{Medicina General, Clínica de Cirugía Plástica Universal. Servicio de Cirugía Plástica. Hospital México.}

Correspondencia: Madelein Centeno Rodríguez. Carlos Centeno Ramírez. Clínica de Cirugía Plástica Universal. Ave. 1*, Calle 24-26. Paseo Colón, San José.
Veinte años más tarde, el Dr. Chedomir Radovan publica su experiencia con expansores tisulares diseñados por él mismo para la reconstrucción mamaria, popularizando de esta forma la técnica.

Posteriormente, Austad y Rose desarrollan el expansor autoinflable, cuyo principio radica en la colocación de sustancias hiperosmolares dentro de una membrana semipermeable, creando así un gradiente de osmolaridad que favorece el paulatino aumento de volumen del expansor.'

Los expansores más utilizados en la actualidad son hechos a partir de silicón y utilizan suero fisiológico para el aumento paulatino de volumen.

Con el correr del tiempo, la aceptación de estos procedimientos y la investigación al respecto ha aumentado en gran cantidad, de tal forma que los estudios son cada vez más detallados, específicos y extensos. Sin duda estos pioneros iniciaron una era de amplio conocimiento cuyo pleno desarrollo está apenas por iniciar.

\section{Técnica de Implantación}

La implantación de un expansor tisular es un proceso que conlleva un cuidadoso análisis de múltiples factores antes del procedimiento quirúrgico. Existen dos indicaciones para la reconstrucción mediante expansores tisulares. La primera es que la cantidad y calidad del tejido adyacente al defecto sean inadecuadas y la segunda que el defecto del sitio donador al crear el colgajo sin expansión sea muy significativo.' En caso de que el paciente presente cualquiera de estas dos situaciones, se procede a evaluar la posición, tamaño y origen del defecto tisular que se desea reconstruir, tomando en cuenta la calidad del tejido que será expandido, el tamaño del expansor que será necesario, la posición de las nuevas incisiones que se realizarán y sus respectivas cicatrices. ${ }^{2.11 \cdot 13}$ Es muy importante seleccionar cuidadosamente los pacientes para este tipo de procedimientos. Argenta y colaboradores mencionan entre las características del paciente idóneo, que sea capaz de comprender el procedimiento que se le va a realizar, que se encuentre muy motivado al respecto y que sea mentalmente competente. Además recomiendan no proponer este proceso a pacientes que no brindan mucha cooperación o que son mentalmente inestables, pues la utilización de expansores tisulares implica una alteración significativa de la imagen corporal por un tiempo bastante prolongado. 14.15 
Un expansor tisular está constituido por el expansor, que es la parte que aloja el suero fisiológico y produce la expansión del tejido; el reservorio, que es una especie de válvula por donde se inyecta transcutáneamente el suero y una conexión entre ambos, cuya longitud puede variar de acuerdo al tipo de expansor (Figura 1). Existen diferentes tamaños y gran variedad de formas, lo cual brinda múltiples alternativas de expansión $^{5.13}$ (Figura 2).

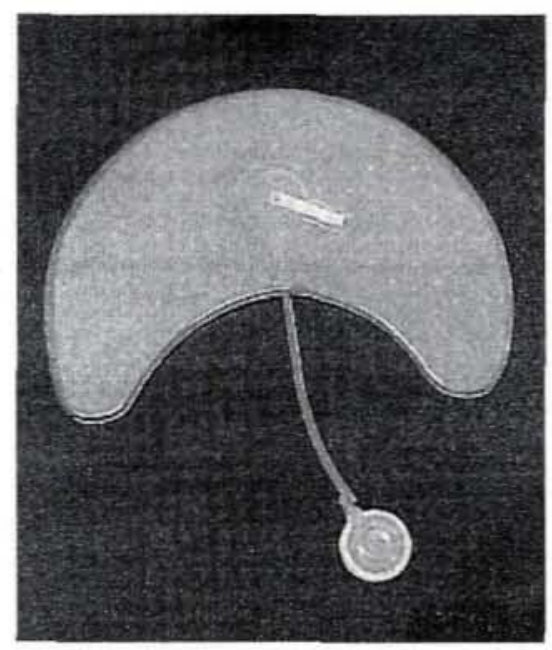

Figura 1. Expansor tisular constituido por el expansor; el reservorio y una conexión entre ambos.

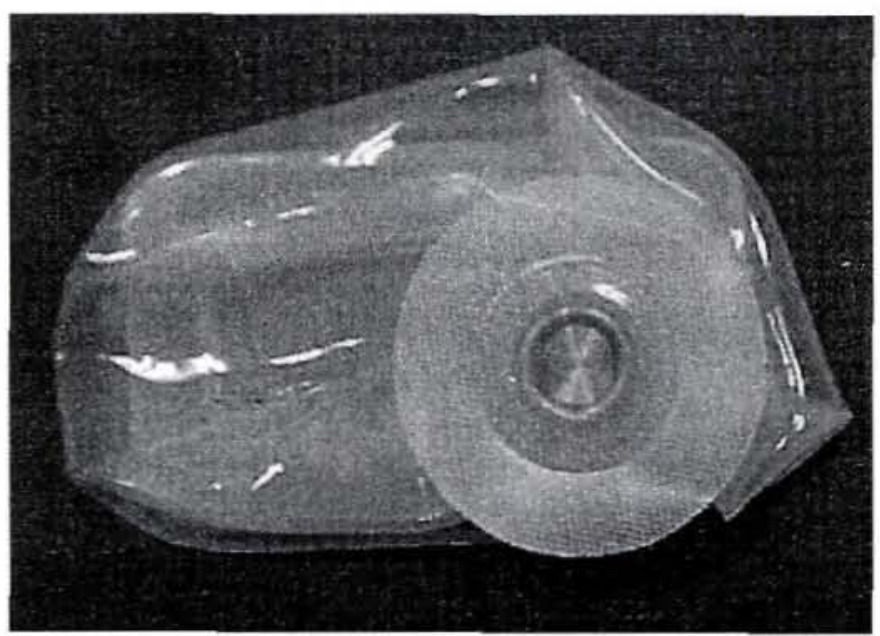

Figura 2. Existen diferentes tamaños y gran variedad de formas, lo cual brinda múltiples alternativas de expansión.

Una vez que se han hecho estas consideraciones, la técnica quirúrgica se divide en dos etapas. La primera etapa consiste en la colocación temporal del expansor hasta alcanzar la expansión deseada, para lo cual es necesario realizar una pequeña incisión perpendicular al eje del expansor y mediante disección roma se crea un sobre de tejido subcutáneo donde se coloca el expansor y otro de menor tamaño para la colocación del reservorio. Se adecua el tamaño de la conexión y la misma se fija con tejido subcutáneo alrededor para evitar la migración del reservorio hacia el expansor."

La inyección transcutánea de volumen debe iniciarse dos semanas después de la implantación y puede realizarse una o dos veces por semana, de acuerdo al tipo de tejido que está siendo expandido. La cantidad de líquido que debe inyectarse es relativa; objetivamente se considera que se debe aumentar el volumen del expansor en un 10 a un $15 \%$, sin embargo en términos subjetivos usualmente se inyecta volumen hasta que la piel sobre el expansor se observe tensa y levemente pálida o el paciente reporte incomodidad extrema. ${ }^{\text {5.1n.17 }} \mathrm{La}$ primera etapa finaliza cuando se alcanza el volumen deseado dentro del expansor.

La segunda etapa consiste en la remoción del expansor y la reconstrucción del defecto inicial mediante la rotación o avance de colgajos. ${ }^{25.10}$

\section{Ventajas y Desventajas}

La expansión de tejidos blandos ofrece muchas ventajas. Permite un incremento controlado de tejidos específicos, incrementa su vascularidad mejorando el aporte sanguíneo y por lo tanto la viabilidad y pronóstico de colgajos; genera suficiente tejido para cubrir el defecto primario así como el sitio donador ${ }^{2}$ y al ser tejido vecino al defecto primario, permite conservar sus mismas características de textura, color, anexos y sensibilidad. ${ }^{818.19}$ Además los tiempos operatorio, de internamiento y recuperación postoperatoria son mínimos en comparación con los procedimientos de colgajos miocutáneos o libres."

Sin embargo, el procedimiento también presenta algunas desventajas ya que obliga a numerosas visitas médicas para aumentar el volumen del expansor, se necesita una segunda intervención quirúrgica para movilizar y utilizar el tejido expandido ${ }^{2.17} \mathrm{y}$ además existe la posibilidad de desarrollar complicaciones que pueden poner en peligro el proceso de expansión.

\section{Cambios Histológicos}

A nivel de epidermis, las alteraciones encontradas con microscopios de luz y electrónicos son controversiales. Argenta y colaboradores reportan en 1985 que los cambios observados antes y después de la expansión tisular no son significativos. ${ }^{15}$ Sin embargo, Pasyk y colaboradores dos años más tarde encuentran un aumento significativo del grosor de la epidermis después de la expansión debido a la casi inmediata elevación de la actividad mitótica de las células. ${ }^{15930}$

Ambos estudios coinciden en el adelgazamiento significativo de la dermis luego de la expansión, sin alteración histológica de glándulas sebáceas o sudoríparas ni de folículos pilosos. ${ }^{\text {1s. }}$ 
El músculo debajo del expansor ha demostrado sufrir atrofia significativa sin alteración funcional,,$^{1920}$ el tejido adiposo es sumamente intolerante a la expansión y rápidamente sufre adelgazamiento de las capas así como disminución del número de adipocitos, aparentemente en forma permanente. ${ }^{15}$

Alrededor del implante, habitualmente se forma una cápsula de tejido fibroso denso compuesto por fibroblastos y fibras colágenas, la cual se adelgaza importantemente al remover el implante. $^{20}$

En relación a la circulación, se produce una rápida proliferación de vasos sanguíneos en el tejido expandido ${ }^{1521}$ lo cual conlleva un mayor aporte sanguíneo, permitiendo así colgajos de mayor superficie y mejorando su evolución. ${ }^{22.25}$

\section{Aplicaciones Clínicas}

La expansión tisular se puede utilizar en muchos casos. Se ha obtenido importante experiencia en reconstrucción mamaria, ${ }^{12.15,16.3426}$ eliminación de defectos del cuero cabelludo, ${ }^{1527.28}$ la cara ${ }^{929}$ y de cabeza y cuello, ${ }^{15.30}$ resección de nevus gigantes, ${ }^{31}$ reconstrucción de tejidos lesionados por quemaduras, ${ }^{6,732}$ así como eliminación de defectos de pared abdominal. ${ }^{3.3 .4}$

\section{Complicaciones}

Durante la reconstrucción de un defecto con expansores tisulares, son múltiples las condiciones que contribuyen a la aparición de complicaciones. Youm y colaboradores mencionan que factores como la corta edad del paciente, utilización de múltiples expansores, el poco entendimiento del proceso de expansión tisular determinado por un bajo nivel educativo y socioeconómico, la dificultad para el acceso a servicios de emergencia, la localización del expansor en tejido cicatrizal, quemado o irradiado y la poca experiencia y habilidad del cirujano, incrementan la posibilidad de sufrir complicaciones. ${ }^{35}$

El porcentaje total de complicaciones varía mucho entre diferentes autores pero en general se encuentra entre $5 \%$ y $65 \%$. $^{36}$ Las complicaciones encontradas en este tipo de procedimientos pueden dividirse en mayores o absolutas y menores o relativas. ${ }^{7,35} \mathrm{La}$ incidencia de ambas categorías según la literatura se resume en la Cuadro 1.

\begin{tabular}{|c|c|c|}
\hline \multicolumn{3}{|c|}{$\begin{array}{c}\text { Cuadro 1 } \\
\text { Incidencia de Complicaciones Mayores y Menores } \\
\text { según la Literatura }\end{array}$} \\
\hline Estudio & $\begin{array}{c}\text { Complicaciones } \\
\text { Mayores }\end{array}$ & $\begin{array}{c}\text { Complicaciones } \\
\text { Menores }\end{array}$ \\
\hline Chun y Rohrich, 1998.' & $12 \%$ & $32 \%$ \\
\hline Pisarsky y col., 1998." & $11 \%$ & $7 \%$ \\
\hline Marks y col., 1987." & $9 \%$ & $9 \%$ \\
\hline Manders y col., 1984: & $24 \%$ & $17 \%$ \\
\hline
\end{tabular}

\section{Complicaciones Mayores o Absolutas}

Este grupo incluye aquellas complicaciones que impiden el proceso de reconstrucción del defecto tisular del paciente, ya que debe interrumpirse la expansión, extraer el implante y esperar por lo menos tres meses para reintentar el procedimiento. ${ }^{7}$ Según Pisarsky y colaboradores ${ }^{32}$ las más frecuentes junto con sus porcentajes de incidencia son:

- Infección $(4,6 \%)$. Puede suceder por contaminación durante la implantación del expansor, inadecuada técnica aséptica al aumentar el volumen periódicamente o cuando la tensión ejerce una fuerza suficiente para abrir la incisión, permitiendo el contacto del expansor con el exterior y por lo tanto la contaminación. El microorganismo más frecuentemente encontrado en estos casos es el Staphylococcus aureus. ${ }^{7.32}$

- Fallo del expansor (3,9\%). Se han reportado casos en los que se produce ruptura de la conexión o salida del suero salino del expansor.

- Exposición del expansor (1,8\%). Esta complicación se da cuando la tensión produce dehiscencia de la herida con la consecuente exposición del expansor.

Radovan menciona además que la sangre bajo el expansor en el caso de un hematoma tiene un efecto tóxico, predisponiendo así a la necrosis del colgajo. En ambos casos la reconstrucción debe interrumpirse, por lo que este autor clasifica el hematoma y la necrosis como complicaciones mayores. ${ }^{5.16}$

\section{Complicaciones Menores o Relativas}

Este grupo de complicaciones se refiere a aquellas que no alteran el proceso de expansión ni interrumpen la reconstrucción del defecto tisular del paciente. ${ }^{5.21}$

Según Pișarsky y colaboradores ${ }^{32}$ las complicaciones menores que se presentan con mayor frecuencia son:

- Úlcera isquémica $(1,8 \%)$. Se produce en los casos en que el aumento de volumen del expansor es muy exagerado, disminuyendo el aporte sanguíneo de la piel sobre el mismo,

- Distorsión de la imagen corporal $(1,1 \%)$. En algunos casos la alteración de la imagen corporal es tan significativa que puede llevar a depresión y sentimientos de rechazo.

- Infección tardía $(1,1 \%)$. El mecanismo de aparición es el mismo que en la infección temprana, con la ventaja de que al producirse el proceso infeccioso tardíamente ya se ha dado cierta expansión tisular que permite reconstruir el defecto.

Con el fin de disminuir la incidencia de complicaciones, Chun y Rohrich recomiendan:? 
- Disecar un sobre de tejido que sea bastante amplio para la colocación del expansor.

- Utilizar expansores de tamaño y forma standard y no hechos a la medida.

- Incorporar drenajes durante la expansión tisular.

- Realizar las incisiones en tejido sano.

- Esperar 10 a 14 días después de la colocación del expansor para iniciar el aumento de volumen.

- Usar puertos (reservorios) incorporados al expansor en lugar de conexiones largas.

Pisarsky y colaboradores además mencionan el lavado del área de cirugía con jabón antibacterial la noche antes de la implantación, administración parenteral de una cefalosporina de primera generación preoperatoriamente y evitar al máximo el rasurado de las zonas quirúrgicas. ${ }^{32}$

Marks y colaboradores insisten en la importancia de realizar una meticulosa hemostasia para evitar la formación de hematomas y la colocación del expansor y reservorio en sitios anatómicos en los que no se ejerza mucha presión ante los cambios de posición del paciente.

Por otra parte, Austad y colaboradores enfatizan que los expansores tisulares no deben utilizarse en la reconstrucción de lesiones traumáticas agudas por la cercanía con tejidos contaminados, lo cual podría predisponer a infección. ${ }^{14}$

\section{Caso Clínico}

Paciente femenina de 44 años de edad, vecina de Puntarenas, que consultó por presentar lesión infiltrativa de dos tercios (medio y distal) de la piel del dorso de la nariz, de varios años de evolución. La lesión fue diagnosticada como carcinoma basocelular y al comprobarse que la cantidad del tejido adyacente al defecto era insuficiente para la reconstrucción, se decidió que la técnica de expansión tisular podía utilizarse en este caso con el fin de crear un colgajo amplio que al rotar, cubriera totalmente el defecto ocasionado por la resección de la lesión nasal.

Se colocó un expansor tisular tubular, de $250 \mathrm{cc}$ de capacidad, en la zona frontal y transoperatoriamente se inició la expansión con $60 \mathrm{cc}$ de suero fisiológico. A las tres semanas de la colocación, se inyectaron $60 \mathrm{cc}$ y cada 7-20 días se aumentó el volumen en un promedio de $30 \mathrm{cc}$ por sesión hasta alcanzar el volumen de 230cc (Figura 3). Luego de cuatro meses de expansión paulatina, la paciente fue llevada a sala de operaciones para resecar el carcinoma basocelular, retirar el expansor tisular y movilizar el colgajo de región frontal hacia la región nasal (Figura 4). Dos semanas después, fue operada para corregir el pedículo del colgajo en su punto de rotación. El colgajo evolucionó positivamente, así como la zona donadora. Actualmente, casi un año después de la resección de la lesión cancerosa y rotación del colgajo, las

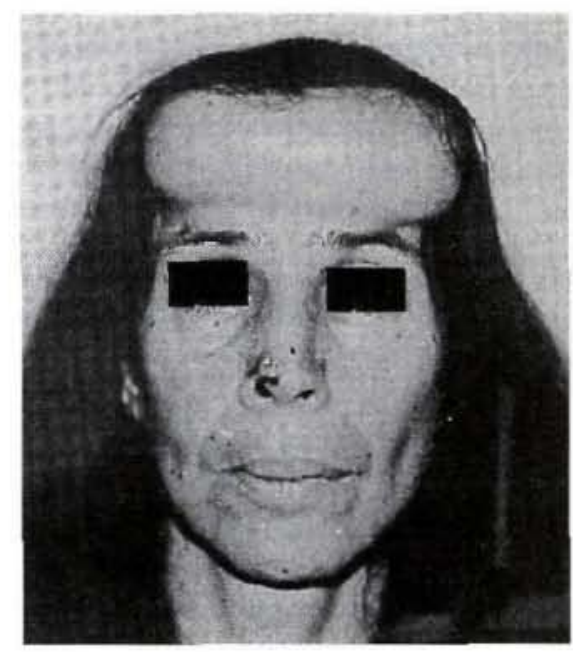

Figura 3. Caso clínico, paciente con expansor tisular tubular en la zona frontal. Los aumentos de volumen se realizaron cada 7-20 días, en un promedio de 30 cc por sesión hasta alcanzar el volumen de $230 \mathrm{cc}$.

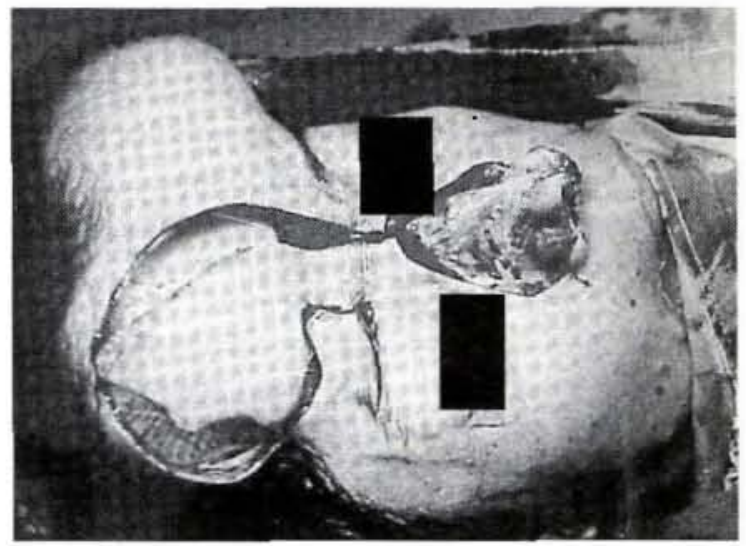

Figura 4. Se reseca el carcinoma basocelular, se retira el expansor tisular y se moviliza el colgajo de la región frontal hacia la región nasal.

cicatrices son prácticamente imperceptibles, la paciente se encuentra ya recuperada y con un aspecto facial muy satisfactorio (Figura 5).

\section{Discusión}

Evidentemente, la colocación de expansores tisulares es un procedimiento que no se encuentra completamente exento de complicaciones. Sin embargo, representan una gran alternativa con la que el médico puede contar gracias a sus múltiples ventajas y buenos resultados. Es posible que las complicaciones observadas se puedan reducir realizando una meticulosa selección de los pacientes en los cuales se quiere aplicar este procedimiento y siguiendo cuidadosamente las recomendaciones resumidas en esta revisión. 


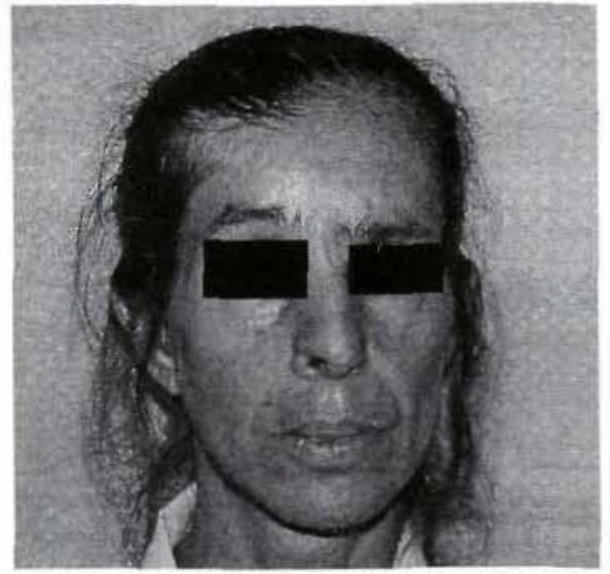

Figura 5. Los aumentos de volumen se realizaron cada 7-20 días, en un promedio de $30 \mathrm{cc}$ por sesión hasta alcanzar el volumen de $230 \mathrm{cc}$.

Lo importante es seguir en una búsqueda constante de técnicas quirúrgicas que ofrezcan al paciente el mejor resultado posible para lograr superar su imagen corporal, con el menor riesgo esperable.

\section{Abstract}

In this article, we present a review of general concepts regarding tissue expansion, history, operative technique, clinical applications, principal complications as well as advantages and disadvantages presented with the use of this alternative in reconstructive surgery.

\section{Referencias}

1. Austad ED. Rose GL. A self-inflating tissue expander. Plast Reconstr Surg 1982: 70(5): 588-593.

2. Argenta L, Vanderkolk C. Tissue expansion in craniofacial surgery. Clin Plast Surg 1987: 14(1): 143-153.

3. Chretien-Marquet B. Rapid intraoperative distension using isotonic saline solution. Plast Reconstr Surg 1995; 96(1): 158-165.

4. Austad E. The origin of expanded tissue. Clin Plast Surg 1987: 14(3): 431-433.

5. Radovan C. Tissue expansion in soft-tissue reconstruction. Plast Reconstr Surg 1984: 74(4): $482-490$.

6. Marks MW. Argenta LC. Thornton JW. Burn management: the role of tissue expansion. Clin Plast Surg 1987: 14(3): 543-548.

7. Chun JT. Rohrich RJ. Versatility of tissue expansion in head and neck burn reconstruction. Ann Plast Surg 1998:41(1): 11-16.

8. Vanderkolk CA. McCann JJ. Knight KR, O'Brien BMcC. Some further characteristics of expanded tissue. Clin Plast Surg 1987: 14(3): $447-453$.

9. Kawashima T. Yamada A. Veda K. Asato H. Harii K. Tissue expansion in facial reconstruction. Plast Reconstr Surg 1994: 94(7): 944-951.

10. Neumann CG. The expansion of an area of skin by progressive distention of a subcutaneous balloon. Plast Reconstr Surg 1957:19: 124-130.
11. Raposio E, Santi P. Computer-aided preoperative planning of tissue expansion. Ann Plast Surg 1997: 39: 416-417.

12. Cohen IK, Turner D. Immediate breast reconstruction with tissue expanders. Clin Plast Surg 1987; 14(3): 491-498.

13. Duits EHA, Molenaar J, van Rappard JHA. The modeling of skin expanders. Plast Reconstr Surg 1989: 83(2): 362-365.

14. Austad ED. Complications in tissue expansion. Clin Plast Surg 1987: 14(3): $549-550$.

15. Argenta LC, Marks MW. Pasyk KA. Advances in tissue expansion. Clin Plast Surg 1985: 12(2): 159-172.

16. Radovan. C. Breast reconstruction after mastectomy using the temporary expander. Plast Reconstr Surg 1982: 69(2): 195-206.

17. Hallock GG, Rice DC. Objective monitoring for safe tissue expansion Plast Reconstr Surg 1986: 77(3): 416-420.

18. Van Beek AL. Adson MH. Tissue expansion in the upper extremity. Clin Plast Surg 1987: 14(3): 535-542.

19. Austad ED, Thomas SB. Pasyk K. Tissue expansion: dividend or loan? Plast Reconstr Surg 1986; 78(1): 63-67.

20. Pasyk KA, Argenta LC. Austad ED. Histopathology of human expanded tissue. Clin Plast Surg 1987; 14(3): 435-445.

21. Manders EK. Schenden MJ, Furrey JA. Hetzler PT. Davis TS. Graham WP. Soft-tissue expansion: concepts and complications. Plast Reconstr Surg 1984; 74(4): 93-507.

22. Hong C, Stark GB, Futrell JW. Elongation of axial blood vessels with a tissue expander. Clin Plast Surg 1987: 14(3): 465-467.

23. Marks MW, Argenta LC. Thornton JW. Rapid expansion: experimental and clinical experience. Clin Plast Surg 1987: 14(3): 455-463.

24. Thornton JW, Marks MW, Izenberg PH. Argenta LC. Expanded myocutaneous flaps: their clinical use. Clin Plast Surg 1987: 14(3): 529 534.

25. Cherry GW. Phil D. Austad E. Pasyk KK. McClatchey K. Rohrich RJ. Increased survival and vascularity of random-pattern skin flaps elevated in controlled, expanded skin. Plast Reconstr Surg 1983; 72(5): 680685

26. Becker. H. The permanent tissue expander. Clin Plast Surg 1987: 14(3): $519-527$.

27. Anderson RD. Expansion-assisted treatment of male pattern baldness. Clin Plast Surg 1987: 14(3): 477-490.

28. Manders EK, Au VK. Wong RKM. Scalp expansion for male pattern baldness. Clin Plast Surg 1987: 14(3): 469-475.

29. Edington HDJ, Mooney MP, Losken A. Hurwitz DJ, Siegel MI. The effects of soft-tissue expansion on lip repair and midfacial growth in a rabbit cleft lip model. Ann Plast Surg 1998: 41(2): 171-179.

30. Antonyshyn O, Gruss J. Zuker R. Mackinnon S. Tissue expansion in head and neck reconstruction. Plast Reconstr Surg 1988: 82(1): 58-68.

31. Perlyn C, Meara JG, Smith JD, Breving KH, Bartlett R. Secondary reconstruction of a giant congenital lentiginous dermal nevus with a serial. large volume tissue expansion. Ann Plast Surg 1999: 43.5 : $546-$ 550.

32. Pisarski GP. Mertens D. Warden GD. Neale HW. Tissue expander complications in the pediatric burn patient. Plast Reconstr Surg 1998: 102(4): 1008-1011.

33. Paletta CE, Huang DB. Dehghan K. Kelly C. The use of tissue expanders in staged abdominal wall reconstruction. Ann Plast Surg 1999: 42(3): 259-265. 
34. Still J, Craft-Coffman B, Law E. Use of pedicled flaps and tissue expanders to reconstruct burn scars of the anterior abdomen and chest wall. Ann Plast Surg 1998; 40(3): 226-228.

35. Youm T, Margiotta M, Kasabian A, Karp N. Complications of tissue expansion in a public hospital. Ann Plast Surg 1999; 42(4): 396-402.
36. Brown MD, Johnson TM. Complications of tissue expansion. J Dermatol Surg Oncol 1993; 19: 1120-1122. 